\title{
TRH Test in Patients with Diabetes Mellitus Type 1 and/or Autoimmune Thyroiditis. Changes in the Pituitary-Thyroid Axis, Reverse T3, Prolactin and Growth Hormone Levels
}

\author{
E. ORLICKÁ ${ }^{1}$, K. VONDRA ${ }^{1}$, M. HILL ${ }^{1}$, J. SKIBOVÁ ${ }^{2}$, I. ŠTERZL $^{3,1}$, V. ZAMRAZIL $^{1}$ \\ ${ }^{1}$ Institute of Endocrinology, Prague, ${ }^{2}$ Institute of Clinical and Experimental Medicine, Prague and \\ ${ }^{3}$ Institute of Immunology and Microbiology of the First Faculty of Medicine and General Teaching \\ Hospital, Prague, Czech Republic
}

Received November 12, 2007

Accepted January 28, 2008

On-line February 13, 2008

\begin{abstract}
Summary
The response of the pituitary- thyroid axis, reverse triiodothyronine (rT3), prolactin, and growth hormone (GH) levels following TRH stimulus (Relefact TRH $200 \mu \mathrm{g} 2$ amp. i.v.) was examined in patients with autoimmune diabetes type 1 (DM1, $\mathrm{n}=30$ ), with autoimmune thyroiditis (AT, $n=25)$, and with concurrent DM1 and AT ( $n=22)$ to evaluate the influence of DM1 and AT of autoimmune pathogenesis on the above-mentioned hormonal parameters. Statistical analysis (ANOVA) showed that: a) the response of TSH did not differ from control groups (C); b) free triiodothyronine (fT3), free thyroxine (fT4) and their ratio in DM1, DM1+AT and C rose in 120 and $180 \mathrm{~min}$, while a similar increase was not seen in AT $(p<0.000001) ; c)$ rT3 was not present in any group, with rT3 levels higher in AT $(p<0.00002)$ and lower in DM1 $(p<0.02) ; d)$ the response of $\mathrm{GH}$ had a paradoxical character in some patients in all groups, most often in DM1 (52 \%, DM1 vs C, p <0.01). The characteristic response difference was not in the peak $\mathrm{GH}$ level, but the delayed return to basal levels in DM1 $(p<0.0001)$ and an abrupt one in AT $(p<0.0001)$. The major findings in DM1 were the differences in $\mathrm{GH}$ response, while significant impairment of pituitary-thyroid axis and PRL response to TRH was absent. AT was associated with impairment of TRH stimulated fT3, fT4, fT3/fT4 response and changes in rT3 levels, in spite of preserved TRH-stimulated TSH secretion. GH response in AT patients was also altered.
\end{abstract}

\section{Key words}

TRH test • Diabetes mellitus type 1 - Autoimmune thyroiditis • Growth hormone • TSH • Free T4 • Free T3 • Reverse T3

\section{Corresponding author}

K. Vondra, Institute of Endocrinology, Národní třída 8, 11694 Prague 1, Czech Republic. E-mail: kvondra@endo.cz

\section{Introduction}

Changes of the production and secretion of thyroid hormones accompany many diseases - e.g. chronic renal failure, some psychiatric disorders etc. (Bartalena et al. 1990). The introduction of the TRH test in 1969 allowed the study of the of thyroid regulation at the hypothalamic and pituitary level in humans. Due to the frequent coexistence of thyroid diseases and diabetes mellitus (Vondra et al. 2005, Bárová et al. 2004, Prázný et al. 2005), the behavior of the hypothalamic-pituitarythyroid axis has been thoroughly studied in patients with diabetes mellitus. A number of authors described its impaired response to TRH stimulus. When evaluating the conclusions of these studies, it is important to realize, that the majority of these studies were done during times when diabetes classification was not specified in terms of pathogenesis, the samples of patients were small and not unified with respect to age and metabolic control of diabetes. Because studies following the response of growth hormone to TRH stimulus are similarly inconclusive, we decided to conduct our own study: we assessed the response of the thyroid stimulating hormone (TSH) secretion, free triiodothyronine (fT3), free thyroxine (fT4), reverse T3 (rT3), prolactin (PRL) and growth hormone $(\mathrm{GH})$ levels after TRH stimulus in patients with type 1 diabetes, autoimmune thyroiditis and with a combination of both diseases. The goal was to acquire more detailed data in well-defined groups of patients and to study the possible influence of 
Table 1. Basic characteristics.

\begin{tabular}{|c|c|c|c|c|c|c|c|c|}
\hline & \multicolumn{2}{|c|}{ Controls } & \multicolumn{2}{|c|}{ DM1 } & \multicolumn{2}{|c|}{ AT } & \multicolumn{2}{|c|}{ DM1+AT } \\
\hline & f & $\mathbf{m}$ & f & $\mathbf{m}$ & f & $\mathbf{m}$ & f & $\mathbf{m}$ \\
\hline$N$ & 14 & 5 & 9 & 21 & 19 & 6 & 15 & 7 \\
\hline \multirow{2}{*}{ Age (years) } & 29.5 & 31 & 33.2 & 37 & 34 & 35 & 36 & 40 \\
\hline & \pm 6.5 & \pm 7.3 & \pm 6.0 & \pm 8.6 & \pm 8.4 & \pm 5.6 & \pm 8 & \pm 9.5 \\
\hline \multirow{2}{*}{$B M I\left(k g / m^{2}\right)$} & 22.78 & 23.34 & 22.83 & 25.36 & 22.87 & 27.02 & 23.49 & 25.35 \\
\hline & \pm 3.34 & \pm 3.14 & \pm 1.66 & \pm 3.15 & \pm 2.829 & \pm 4.911 & \pm 3.279 & \pm 3.426 \\
\hline Duration of & \multirow{2}{*}{0} & \multirow{2}{*}{0} & 15.0 & 12.6 & \multirow{2}{*}{0} & \multirow{2}{*}{0} & 12 & 14 \\
\hline DM (years) & & & \pm 6.8 & \pm 7.2 & & & \pm 7 & \pm 7.1 \\
\hline C-peptide & 0.630 & 0.455 & 0.022 & 0.096 & 0.5595 & 0.9617 & 0.0793 & 0.075 \\
\hline$(\mathrm{nmol} / \mathrm{l})$ & \pm 0.181 & \pm 0.117 & \pm 0.059 & \pm 0.173 & \pm 0.1663 & \pm 0.4276 & \pm 0.1226 & \pm 0.1656 \\
\hline Glycaemia & 4.32 & 4.38 & 7.66 & 9.17 & 4.27 & 5.0 & 8.48 & 7.76 \\
\hline$(\mathrm{mmol} / \mathrm{l})$ & \pm 0.30 & \pm 0.50 & \pm 3.54 & \pm 4.20 & \pm 0.68 & \pm 0.95 & \pm 2.83 & \pm 2.97 \\
\hline & 3.83 & 3.76 & 7.42 & 7.69 & 3.96 & 4.42 & 7.77 & 7.17 \\
\hline HbAlc (\%) & \pm 0.40 & \pm 0.20 & \pm 1.97 & \pm 2.30 & \pm 0.31 & \pm 0.82 & \pm 1.81 & \pm 2.3 \\
\hline
\end{tabular}

DM1 - diabetes mellitus type 1, AT - autoimmune thyroiditis, $\mathrm{f}$ - female, $\mathrm{m}$ - male, BMI - body mass index, HbA1c - glycosylated hemoglobin

autoimmune pathogenesis of type 1 diabetes and autoimmune thyroiditis on the hormonal parameters mentioned above.

\section{Methods and Subjects}

Ninety-six patients (57 women and 39 men) participated in the study. Thirty suffered from diabetes mellitus type 1 (DM1) (9 women, 21 men) without any other autoimmune disease, 22 had DM1 along with chronic autoimmune thyroiditis (AT) (15 women, 7 men), and 25 patients had only AT (19 women, 6 men). There were 19 healthy controls (14 women, 5 men). Characteristics of the patients, such as age, body mass index (BMI), diabetes duration, C-peptide level and current and long-term compensation data are shown in Table 1. All patients with AT had positive autoantibodies against microsomal fraction of the thyroid gland and/or against thyreoglobulin and thyroiditis confirmed by ultrasonography. All used substitution therapy by thyroxine and were in euthyroidism. None of the patients suffered from any serious disease (particularly depression, epilepsy, renal insufficiency etc), which could influence the course of the TRH test. This was confirmed by medical history, clinical and laboratory examination. Before entering the study written informed consent was obtained after written and oral information. The study protocol was approved by the Institutional Ethical Committe.

TRH test

The TRH test was performed after an overnight fast at $7 \mathrm{AM}$ at the Clinical Research Unit of the Institute of Endocrinology, Prague. The patients with DM1 applied the last dose of basal insulin in the evening before the test. Breakfast prandial insulin was given with a meal after the test. After obtaining the 0 min blood sample, 400 $\mu \mathrm{g}$ TRH i. v. was administered, followed by drawing blood samples at 20,60,120, and 180 minutes. In $0-120$ minutes, TSH, fT4, fT3, PRL and GH were measured, in 180 minutes only fT4 and fT3 were evaluated. Reverse T3 was assessed in 0, 120 and $180 \mathrm{~min}$. In addition, Cpeptide, glycaemia, HbA1c and basic biochemical parameters to exclude other serious diseases were measured at time 0 . Because of the known gender differences in TRH-stimulated TSH response the data were evaluated separately in men and women.

\section{Analytical methods}

Serum glucose concentration was determined by enzymatic method with hexokinase (Integra 400 Plus, Roche, measurement range $0.0-40.0 \mathrm{mmol} / \mathrm{l}$, detection 
limit $0.033 \mathrm{mmol} / 1$, intraassay $1.7 \% \mathrm{cv}$, interassay $2.6 \%$ $\mathrm{cv})$.

Growth hormone (analytical sensitivity 0,1 $\mathrm{mIU} / \mathrm{L}$, intraassay $1.5 \% \mathrm{cv}$, interassay $14 \% \mathrm{cv}$, measurement range $0.1-100 \mathrm{mIU} / \mathrm{L}$ ) was measured by immunoradiometric assay (IRMA, Immunotech, Prague, Czech Republic).

C peptide, prolactin, fT4, fT3 and TSH were determined by electrochemiluminescent immunoanalysis (ECLIA) using Modular Analytics E170 Roche, Mannheim, Germany.

C peptide, analytical sensitivity $0.003 \mathrm{nmol} / \mathrm{l}$, intraassay $1.5 \% \mathrm{cv}$, interassay $2.3 \% \mathrm{cv}$, measurement range $0.003-13.3 \mathrm{nmol} / \mathrm{l}$.

Prolactin, measurement range $0.070-470$ $\mathrm{ng} / \mathrm{ml}$, intraassay $1.7 \% \mathrm{cv}$, interassay $2.0 \% \mathrm{cv}$, analytical sensitivity $0.047 \mathrm{ng} / \mathrm{ml}$.

Super sensitive TSH, measurement range 0.005 $100.0 \mathrm{mIU} / 1$, intraassay $3 \% \mathrm{cv}$, interassay $7.2 \% \mathrm{cv}$, analytical sensitivity $0.005 \mathrm{mIU} / \mathrm{l}$.

Free T4, measurement range 0.300-100.0 pmol/1, intraassay $2 \% \mathrm{cv}$, interassay $4.8 \% \mathrm{cv}$, analytical sensitivity $0.300 \mathrm{pmol} / \mathrm{l}$.

Free T3, measurement range 0.400-50.0 pmol/1, intraassay $2 \% \mathrm{cv}$, interassay $3.4 \% \mathrm{cv}$, analytical sensitivity $0.400 \mathrm{pmol} / 1$.

Reverse T3 was determined with the aid of RIA (125 I), Biocode Biotechnology, Belgium, analytical sensitivity $0.5 \mathrm{ng} / \mathrm{dl}$, intraassay $6.1 \% \mathrm{cv}$, interassay 6.9 $\% \mathrm{cv}$, measurement range $0.5-300 \mathrm{ng} / \mathrm{dl}$.

\section{Statistical data analysis}

The differences in the status of diabetes status (DM1) and autoimmune thyroiditis status (AT) over time were evaluated by Repeated measures ANOVA model including the following factors: DM1 and AT as the between-factors, Subject factor, Time as the within-factor and all possible factor interactions. The interaction terms indicated whether or not the shapes of the time profiles differed according to DM1 and/or AT or not. The differences between subgroups were evaluated using least significant difference multiple comparisons. The statistical significance $\mathrm{p}<0.05$ was chosen for both ANOVA testing and multiple comparisons. Due to the non-Gaussian data distribution in all dependent variables, the data underwent power transformations to attain distributional symmetry and a constant variance in the data as well as in the residuals. The non-homogeneities were detected using residual diagnostics. The

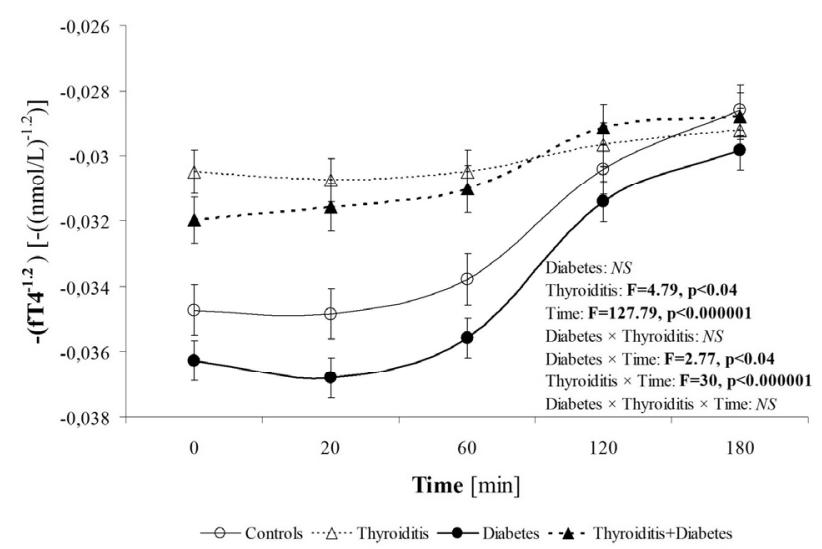

Fig. 1. Response of fT4.

experimental points with absolute values of Studentized residual (after data transformation) greater than 3 were excluded from the analysis. These excluded results were less than $5 \%$ of the total measured results.

Pearson correlation coefficients and partial correlation coefficients were assessed. Area under curve (AUC) was calculated for $\mathrm{GH}$ based on the values measured during the TRH test.

Statistical software Statgraphics Plus v. 5.1 from Manugistics (Rockville, MD, USA) and NCSS 2002 from Number Cruncher Statistical Systems (Kaysville, UT, USA) was used for the data analysis.

\section{Results}

\section{Response of TSH}

Statistical evaluation was performed separately by gender and did not show any significant differences in TSH responses between the different groups. The highest levels of TSH were found in minute 20 after TRH administration, followed by a slow decrease towards baseline levels.

\section{Response of fT4 and fT3}

Results are shown in Figures 1, 2 and 4. There was a significant difference in the response of fT4, fT3 and fT3 / fT4 ratio between the patient group with isolated AT and other groups, where thyroid hormones were increased in the 120th and 180th minute, while in patients with isolated AT a comparable increase was not observed. Groups of patients with isolated DM1, with DM1 and AT and controls did not exhibit any differences with respect to one another. 


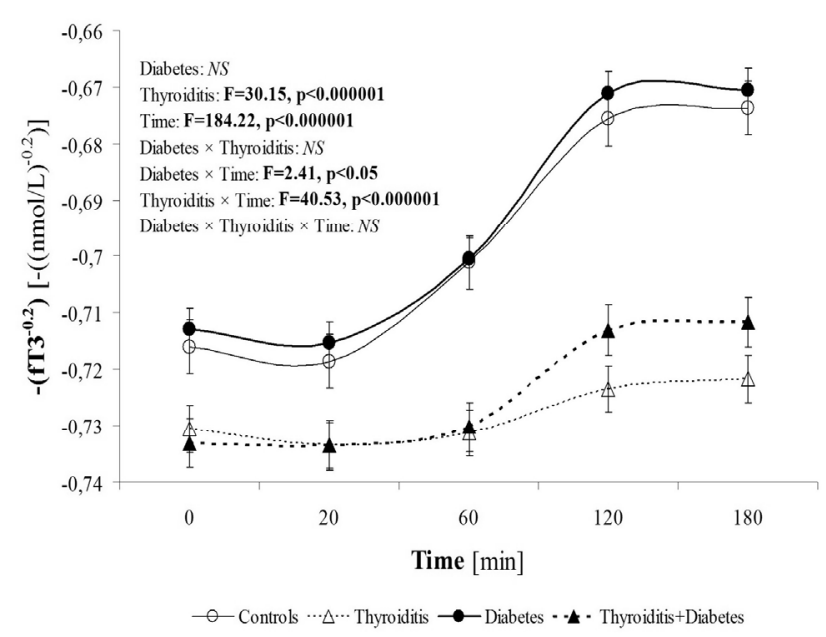

Fig. 2. Response of fT3.

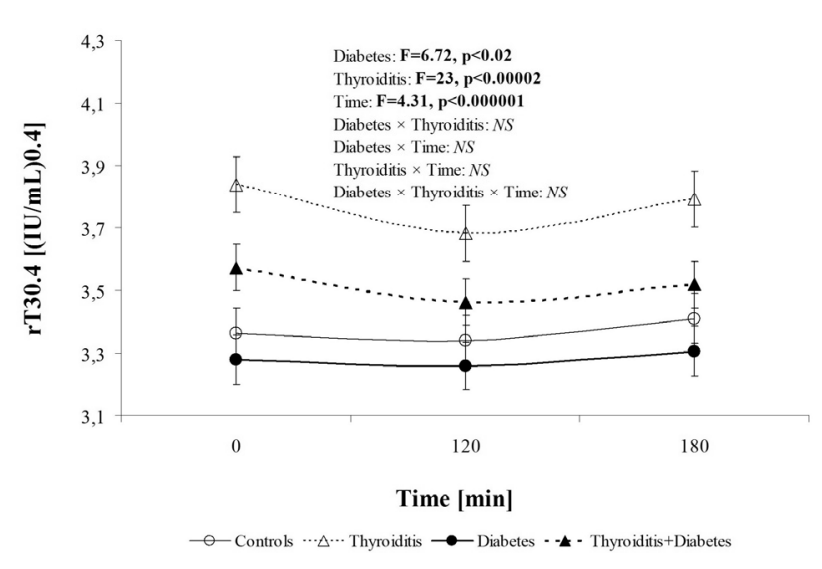

Fig. 3. Response of rT3.

Response of reverse T3

Results are shown in Figure 3. The response of reverse T3 to TRH stimulus over time did not differ between groups. In patients with isolated AT, rT3 values were significantly higher $(\mathrm{p}<0.00002)$ and in the isolated DM1 group rT3 values were lower with marginal significance $(\mathrm{p}<0.02)$.

In the whole sample of patients and controls, rT3 showed significant negative correlation with the fT3/fT4 ratio at time zero $(\mathrm{r}-0.5648, \mathrm{p}<0.001)$, at $120 \mathrm{~min}(\mathrm{r}-$ $0.5161, \mathrm{p}<0.001)$ and at $180 \min (\mathrm{r}-0.6280, \mathrm{p}<0.001)$ of the TRH test. Significant correlation between rT3 and the fT3/fT4 ratio was demonstrated in patients with DM1 (with and without AT): $0 \min (\mathrm{r}-0.4780, \mathrm{p}<0.01), 120$ $\min (\mathrm{r}-0.4855, \mathrm{p}<0.01), 180 \min (\mathrm{r}-0.5518, \mathrm{p}<0.001)$.

\section{Response of growth hormone}

The results concerning the response of growth hormone to TRH stimulus are shown in the Figure 5, showing that patient groups with isolated DM1

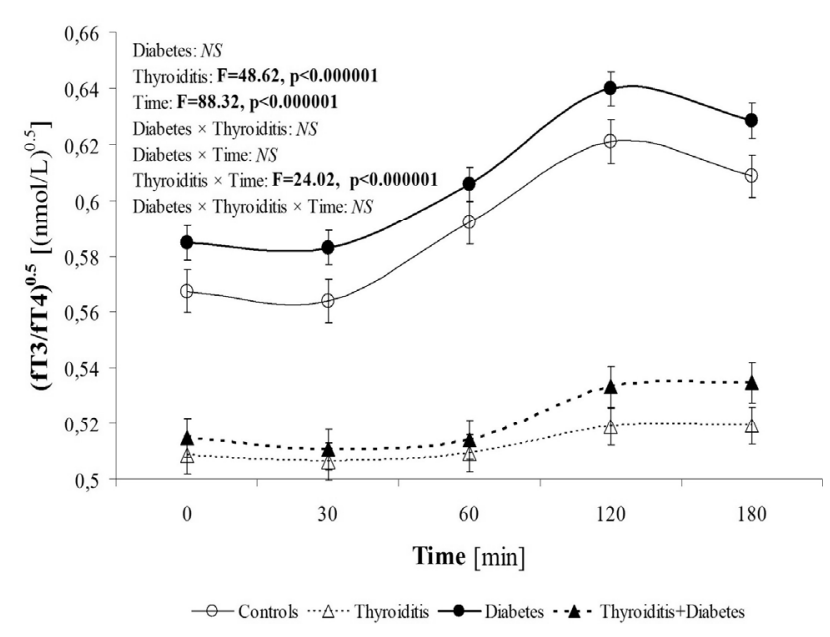

Fig. 4. Response of fT3/fT4.

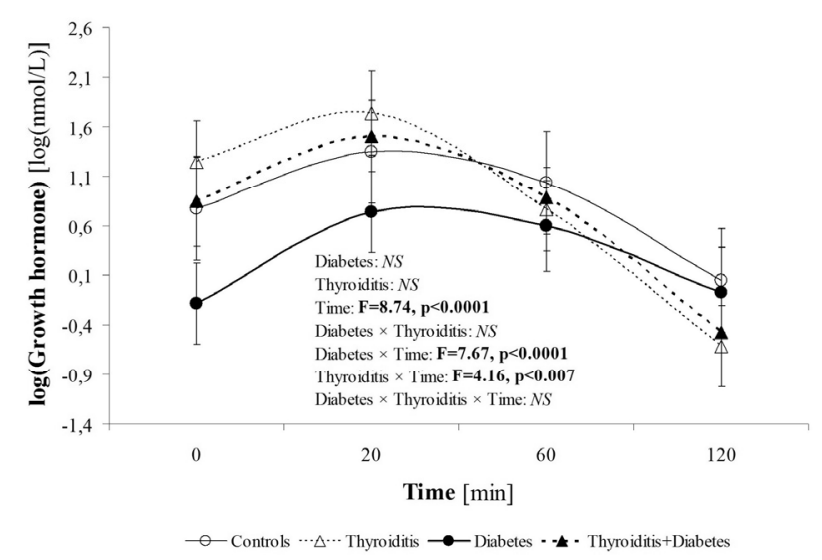

Fig. 5. Response of GH.

$(\mathrm{p}<0.0001)$ and isolated AT $(\mathrm{p}<0.007)$ differed significantly from controls. When compared with healthy controls, patients with DM1 had insignificantly lower basal levels of GH and the peak at $20 \mathrm{~min}$ was followed by a very slow decrease. GH levels had still not returned to their basal values at the end of the testing period (120 min). Unlike patients with DM1, patients with AT had insignificantly higher basal level of GH and the peak at $20 \mathrm{~min}$ was followed by a fast return to original values. At 60 min GH levels were lower than the basal levels at the beginning of the test.

A paradoxical response of GH to TRH (increase of GH caused by TRH stimulus of more than $100 \%$ at min 20 of the TRH test) was present in $48.9 \%$ patients with DM1 (53.9 \% of patients with isolated DM1 and $42.9 \%$ of patients with DM1 + AT). This type of response was observed in other patient groups as well but was less frequent, specifically $25 \%$ of healthy controls and $37.5 \%$ of patients with isolated AT. The difference in the occurrence of this paradoxical response between 
patients with isolated DM1 and controls was statistically significant $(\mathrm{p}<0.1)$.

The value of AUC GH in patients with isolated $\mathrm{DM}$ did not correlate with either glycosylated $\mathrm{Hb}(\mathrm{r}-$ 0.01 , ns), nor with C-peptide levels $(\mathrm{r}-0.1, \mathrm{~ns})$. These correlations remained insignificant even after removing the effect of BMI.

\section{Response of prolactin}

No statistically significant differences were found between groups studied in the response of prolactin.

\section{Discussion}

The influence of some diseases (e.g. depression, schizophrenia) on the hypothalamic- pituitary-thyroid axis is well known and has been well documented. The influence of diabetes on this axis is not clear, although a number of works on this topic have been published. Currently, the subject does not draw much attention, despite the discovery of and a close clinical use of analogue TRH.

The conclusions of studies on animals with streptozocine-induced diabetes are relatively unambiguous. It was shown that diabetes in rats leads to damage in the hypothalamic- pituitary-thyroid axis on several levels. Decreased content of TRH in the hypothalamus along with a decreased concentration of TSH in serum (Gonzales et al. 1980), decreased secretion of TRH from the hypothalamus (Rondeel et al. 1992), lower release of TSH, lower release of TSH from cells in the response to TRH stimulus, lower content of TSH in anterior pituitary cells (Chamras and Hershman 1990) and lowering of the thyroid response to TSH (Bagchi et al. 1981) were observed in these animals. In addition, morphological changes in the neurons of the hypothalamus were observed using electron microscopy. They included changes in the accumulation of glycogen, loss of organelles, irregularities in the nucleus indicating serious cell damage (Bestetti and Rossi 1980). It is hypothesized that the impairment of serotonin turnover in the brain stem plays an important role in the reduced function of the hypothalamic- pituitary -thyroid axis (Henley and Bellush 1992).

Along with experimental animal studies, the influence of diabetes was studied in humans. The majority of the papers come from the 70's and 80 's years when the testing flourished. The results of these studies, however, are quite ambiguous, describing lowered (Naeije et al. 1978), normal (Leroith et al. 1980, MacFarlane et al. 1984, Morley et al. 1978, Harrower 1980) and increased (Andrade et al. 1977) TSH response to the TRH stimulus. The variance can be explained by very incoherent patient samples (diabetes was ill-defined in terms of pathogenesis, onset and duration, age, different metabolic control). In our work we emphasized the homogeneity of our patient group: we chose patients with autoimmune diabetes type 1 , manifested in postadolescent middle age without accompanying diseases.

In the 1990's two studies on the subject were published. To evaluate the axis the authors did not use the TRH test, but measured the night TSH peak instead (Bartalena et al. 1993). They showed that in patients with poorly compensated diabetes, the night TSH peak decreases. After improved metabolic control the situation normalizes. In a study on C-peptide-negative patients with DM1 (Coiro et al. 1997), lowered TSH peak was also demonstrated, but after achieving metabolic control the night peak did not normalize. Since we were interested in the influence of diabetes itself and not the consequences of poor metabolic control or insufficient functional reserves of the beta-cells, we chose DM1 patients with adequate metabolic control with clinically insignificant values of C-peptide $(<0.09 \mathrm{nmol} / \mathrm{l})$.

We observed the pituitary-thyroid axis after the TRH stimulus on three levels: pituitary level by monitoring TSH levels, thyroid level by monitoring the response of free thyroid hormones, and peripheral level by determination rT3 levels. Based on the previous doseresponse study of Snyder and Utiger (1972) we have chosen the bolus $400 \mu \mathrm{g}$ of TRH. The above-mentioned authors demonstrated that TSH response was increased with increasing dose of TRH and reached maximum at $400 \mu \mathrm{g}$.

Statistical analysis with the aid of the ANOVA method showed that the TSH response to the TRH stimulus did not differ in DM1 patients with or without AT, or with isolated AT from the healthy controls. It therefore appears that autoimmune genesis of DM1 and its polyglandular form in patients with DM1 associated with AT does not significantly influence TSH secretion. It seems that the same conclusion can be made even for isolated thyroid autoimmunity in euthyroid situation.

The response of thyroid hormones following TRH stimulus was observed by monitoring the changes in the fT4 and fT3 levels, which are considered as hormonally efficient. Their response in patients with 
isolated DM1 did not differ from control subjects. In patients with isolated AT in contrast to DM1 group, a significant response of free thyroid hormones was not present. We believe this lack of thyroid gland response during the TRH test in patients with AT can be explained by lowered functional capacity of the thyroid affected by the autoimmune inflammation.

Under physiological conditions the total levels of T3 in blood results from two sources: the thyroid gland production, and conversion of T4 to T3 mostly in liver (deiodase 1). The question is whether in our patients with lowered endogenous production of $\mathrm{T} 3$ in the thyroid as a consequence of AT, a compensatory increase in peripheral conversion occurred such that the fT3/fT4 ratio in patients with AT on thyroxine substitution therapy was comparable with controls or diabetic patients without AT. However, the significantly lower ratio of fT3/fT4 which was observed in patients with AT does not point towards increased peripheral conversion. A tendency towards higher levels of fT4 in patients with AT on substitution therapy with thyroxine could be adjusted by conversion to rT3 (deiodase 3), as suggested by significantly higher basal levels of rT3 $(\mathrm{p}<0.00002)$ in patients with AT.

Judging from the invariable values of rT3 during the TRH test in all patient groups, it appears there is a minimal or no influence of TRH on the peripheral conversion of T4 to rT3 or on the activity of deiodases 3 effecting this conversion in healthy subjects, as well as patients with thyroid autoimmunity or autoimmune diabetes.

At 60 min during the TRH test an increase in the fT3/fT4 ratio which peaked at $120 \mathrm{~min}$, followed by a slow decrease, was observed in $\mathrm{C}$ and groups without AT. It can be assumed that besides the increased production of $\mathrm{T} 3$ by the thyroid, the increase in the fT3/fT4 ratio during the second half of the test is primarily due to by increased peripheral conversion of T4, the production of which in the thyroid is15-fold higher than that of T3. (Visser 2002). In patients with $\mathrm{AT}$, the ratio fT3/fT4 during the TRH test remained unchanged. This is not surprising as the situation following TRH stimulus in AT patients characterized by the lack of thyroid hormone secretion response does not differ from the basal conditions prior to the TRH stimulus.

It has been repeatedly described in literature (e.g. Kabadi 1986, Radetti et al. 1985) that patients with poorly compensated DM show decreased the activity of deiodases 1 , followed by the appearance of low T3 syndrome, and the activity of deiodase 3 is increased followed by increased levels of rT3. We observed some of these relationships in our subjects as well. In our wellcompensated patients with DM1, rT3 levels were lower at the margin of significance $(p<0.02)$ and the levels of fT3 and the fT3/fT4 ratio did not differ from control levels. In patients with isolated DM1 and in association with AT we showed a significantly negative correlation between rT3 levels and the fT3/fT4 ratio.

The results of studies following the response of the growth hormone on TRH stimulus in patients with DM are ambiguous. Basal levels of GH are described as being in the normal range in diabetes patients (Blickle et al. 1982, Giampetro et al. 1990) or increased (Pan et al. 1989). The majority of authors agree with one another that in a portion or in the majority of patients with DM1 an increased response of GH to TRH is present (Harrower 1980, Ceda et al. 1981, Barbarino et al. 1992, Blickle et al. 1982, Ceda et al. 1982, Dasmahapatra et al. 1981, Krassowski et al. 1984, Pan et al. 1989, Vanelli et al. 1986, Sagese et al. 1992). Some authors describe the socalled paradoxical response of $\mathrm{GH}, \mathrm{i}$. e. the increase in GH by $100 \%$ with respect to basal levels before $30 \mathrm{~min}$ of the TRH test in some DM patients.

The majority of these works followed the response of $\mathrm{GH}$ to TRH only in patients with DM1 (Blickle et al. 1982, Barbarino et al. 1992, Ceda et al. 1982, Sagese et al. 1992). In two studies the response of GH to TRH was compared in patients with diabetes type 1 and 2. In DM1 patients an increased response was observed, while in patients with diabetes type 2, no such increased response was observed (Pan et al. 1989, Krassowski et al. 1984).

The question remains as to which factors influence the increased $\mathrm{GH}$ response to TRH in some diabetes patients. A positive correlation exists between basal values of $\mathrm{GH}$ and the $\mathrm{GH}$ peak after TRH administration (Ceda et al. 1982, Dasmahapatra et al. 1981) and a negative correlation between age and the peak level (Pan et al. 1989, Ceda et al. 1982). The effect of diabetes compensation is crucial to influencing the GH response according to some authors and in patients with good glycemic control the GH response to TRH is normal (Giampetro et al. 1990). In the majority of works, however, the values of glyceamia and glycosylated $\mathrm{Hb}$ before the examination does not have any influence on the GH response to TRH (Ceda et al. 1982, Dasmahapatra et al. 1981, Krassowski et al. 1984, Vanelli et al. 1986, Sagese et al. 1992). Würzburger et al. 
(1990) found that the portion of patients with increased GH reponse to TRH is C-peptide negative, while in patients with remaining residual activity of the beta cells GH does not increase after TRH stimulus.

Fewer works discussed the GH response to TRH in patients with thyroid disease. In experiments on rats increased GH response to TRH in animals with hypothyreosis and a lowered response in animals with hyperthyreosis were observed (Chihara et al. 1976). In agreement with this observation is the increased GH response to TRH stimulus in patients with primary hypothyreosis (Hamada et al. 1976, Hanew et al. 1995, Baldini et al. 1992). In a study (Faggiano et al. 1985) the response of GH to TRH did not completely normalize even after euthyrosis was achieved by substitution therapy. The authors therefore conluded that the regulation of $\mathrm{GH}$ secretion was impaired in patients with primary hypothyreosis. Another study argues that insufficient regulation by somatostatin causes the hypersecretion of GH in primary hypothyreosis (Baldini et al. 1992). It is necessary to note, that the abovementioned studies originated at the beginning of 1970 and 1990, respectively, when routine methods for thyroidal autoimmunity were not yet available.

In our study we observed the so-called paradoxical GH response to TRH in nearly half of the patients with DM1, which agrees with literature. The paradoxical response occurred in $37.5 \%$ of patients with isolated AT and, in contrast to the literature, in $25 \%$ of healthy controls. It cannot therefore be stated that the paradoxical response is specific for patients with DM1, although it is more frequent in this group. This findings may should be taken in acount by endocrinologists dealing with acromegalic patients with concomitant DM. The paradoxical response of GH to TRH stimulation may be caused by diabetes and not by relapse of acromegaly (Jarkovská et al. 2006).

The main characteristic of the GH response to TRH stimulus in patients with diabetes in comparison to controls is not the maximal GH level after TRH administration, but a delayed return to the basal levels. Similarly, the main difference between the TRHstimulated GH response in patients with AT and controls is not the peak level, but an abrupt return to the basal levels. The clinical significance of the differences observed in these patients is not clear and will require further studies.

When looking for a response to factors which influence the change in the GH response after TRH stimulus we used Pearson correlation analysis. No correlation was found beween $\mathrm{AUC}$ of $\mathrm{GH}$ and glycosylated hemoglobin or with C-peptide levels in patients with DM1, even after removing the effect of BMI.

In agreement with previous works (Leroith et al. 1980, Morley et al. 1978) we did not find a difference in the response of prolactin to TSH in patients suffering from diabetes or autoimmune thyroiditis.

In conclusion we could say that results we gained in well-defined groups of patients suffering from autoimmune type 1 diabetes and autoimmune thyroiditis revealed that: a) the major finding in patients with DM1 were the differences in TRH-stimulated GH response while significant impairment of pituitary-thyroid axis and PRL response to TRH was absent; $b$ ) on the contrary in patients with AT, a lack of of fT3, fT4 and fT3/fT4 response and changes in rT3 levels were found as characteristic in spite of preserved TRH-stimulated TSH secretion. The GH response in AT patients was also altered.

\section{Conflict of Interest}

There is no conflict of interest.

\section{Acknowledgements}

The work was supported by the Institutional research plan No. MSM0021620812 from the Czech Ministry of Education, Youth and Sports.

\section{References}

ANDRADE SF, KANITZ MI, POVOA JRH: Study of thyrotropic reserve in diabetics of adult type. Acta Biol Med Ger 36: 1479-1481, 1977.

BAGCHI N, BROWN TR, SHIVERS B, LUCAS S, MACK RE: Decreased thyroidal response to thyrotropin in diabetic mice. Endocrinology 109: 1428-1432, 1981.

BALDINI M, CATANIA A, ORSATTI A, MANFRREDI MG, MOTTA P, CANTALAMSA L: Inhibitory effect of somatostatin on abnormal GH response to TRH in primary hypothyroidism. Exp Clin Endocrinol 99: 80-83, 1992. 
BARBARINO A, CORSELLO SM, TOFANI A, SCIUTO R, DELLA CASA S, ROTA CA, COLASANTI S, BARINI A: Corticotropin-releasing hormone inhibition of paradoxical growth hormone response to thyrotropinreleasing hormone in insulin dependent diabetics. Metabolism 41: 949-953, 1992.

BÁROVÁ H, PERUŠIČOVÁ J, HILL M, ŠTERZL I, VONDRA K, MAŠEK Z: Anti-GAD-positive patients with type 1 diabetes mellitus have higher prevalence of autoimmune thyroiditis than anti-GAD-negative patients with type 1 and type 2 diabetes mellitus. Physiol Res 53: 279-286, 2004.

BARTALENA L, PACCHIAROTTI A, PALLA R, ANTONANGELI L, MAMMOLI C, MONZANI F, DE NEGRI F, PANICHI V, MARTINO E, BASCHIERI L: Lack of nocturnal serum thyrotropin (TSH) surge in patients with chronic renal failure undergoing regular maintance haemofiltration. Clin Nephrol 34: 30-34, 1990.

BARTALENA L, COSSU E, GRASSO L, VELLUZZI F, LOVISELLI A, CIRILLO R, MARTINO E: Relationship between nocturnal serum thyrotropin peak and metabolic control in diabetic patients. $J$ Clin Endocrinol Metab 76: 983-987, 1993.

BESTETTI G, ROSSI GL: Hypothalamic lesions in rats with long-term streptozocin-induced diabetes mellitus. A semiquantitative light- and electron-microscopic study. Acta Neuropathol (Berl) 52: 119-127,1980.

BLICKLE JF, SCHLIEGER JL, DE LAHARPE F, STEPHAN F: Growth hormone response to thyrotropin-releasing hormone in insulin-dependent diabetics with or without severe microvascular lesions. Diabetes Metab 8: 197201, 1982.

CEDA GP, VALENTI G, SPERONI G, BUTTUTINI U: Some aspects of pituitary function in the male diabetic. J Androl 3: 162-168, 1981.

CEDA GP, SPERONI G, DALL'AGLIO E, VALENTI G, BUTTURINI U: Nonspecific growth hormone responses to thyrotropin-releasing hormone in insulin-dependent diabetes: sex- and age-related pituitary responsivness. J Clin Endocrinol Metab 55: 170-174, 1982.

CHAMRAS H, HERSHMAN JM: Effect of diabetes mellitus on thyrotropin reease from isolated rat thyrotrophs. Am $J$ Med Sci 300: 16-21, 1990.

CHIHARA K, KATO Y, OHGO S, IWASAKI Y, MAEDA K: Effects of hyperthyroidism and hypothyroidism on rat growth hormone release induced by thyrotropin-releasing hormone. Endocrinology 98: 1396-400, 1976.

COIRO V, VOLPI R, MARCHESI C, CAPRETTI L, SPERONI G, CHIODERA P: Influence of residual C-peptide secretion on nocturnal serum TSH peak in well-controlled diabetic patients. Clin Endocrinol 47: 305-310, 1997.

DASMAHAPATRA A, URDANIVIA E, COHEN MP: Growth hormone response to thyrotropin-releasing hormone in diabetes. J Clin Endocrinol Metab 52: 859-862, 1981.

FAGGIANO M, CRISCUOLO T, GRAZIANI M, IORIO S, PISANO G, SINISI AM, BELLASTELLA A.: Persistent TRH-induced growth hormone release after short-term and long-term replacement therapy in primary congenital hypothyroidism. Clin Endocrinol (Oxf.) 23: 61-66, 1985.

GIAMPETRO O, FERDEGHINI M, MICCOLI R, GREGORI G, PENNO G, BERTOLI S, NAVALESI R: Inappropriate growth hormone response to thyrotropin-releasing hormone occurs infrequently in well-regulated diabetes mellitus. Acta Diabetol Lat 27: 119-127, 1990.

GONZÁLEZ C, MONTOYA E, JOLÍN T: Effect of streptozocin diabetes on the hypothalamic-pituitary-thyroid axis in the rat. Endocrinology 107: 2099-2103, 1980.

HAMADA N, UOI K, NISHIZAWA Y, OKAMOTO T, HASEGAWA K: Increase of serum GH concentration following TRH injection in patients with primary hypothyroidism. Endocrinol Jpn 23: 5-10, 1976.

HANEW K, UTSUMI A, SUQAWARA A, TANAKA A, FUKAZAWA H, YOSHIDA K, ABE K: Enhanced plasma GH responses to simulataneous administration of TRH and GHRH in patients with primary hypothyroidism. Endocr J 42: 43-47, 1995.

HARROWER AD: Growth hormone, prolactin and thyrotropin response to thyrotropin-releasing hormone in diabetic patients. Postgrad Med J 56: 481-484, 1980.

HENLEY WN, BELLUSH LL: Streptozocin-induced decreases in serotonin turnover are prevented by thyroidectomy. Neuroendocrinology 56: 354-363, 1992. 
JARKOVSKÁ Z, ROSICKÁ M, MAREK J, HÁNA V, WEISS V, JUSTOVÁ V, LACINOVÁ Z, HALUZÍK M, KRŠEK M: Plasma levels of total and active ghrelin in acromegaly and growth hormone deficiency. Physiol Res 55: 175-181, 2006.

KABADI UM: Serum T3 and reverse T3 concentrations:indices of metabolic control in diabetes mellitus. Diabetes Res 8: 417-421, 1986.

KRASSOWSKI J, JESKE W, ZGLICZYŃSKI S: TRH-induced growth hormone release in insulin-dependent diabetes mellitus. Horm Metab Res 16 (Suppl 1): 119-122, 1984.

LEROITH D, SHAPIRO M, LUBOSHITSKY R, SPITZ IM: The hypothalamic-pituitary axis in diabetes mellitus. Horm Metab Res 12: 608-611, 1980.

MACFARLANE IA, SHEPPARD MC, BLACK EG, GILBEY S, WRIGHT AD: The hypothalamic-pituitary-thyroid axis in type 1 diabetes: influence of diabetic metabolic control. Acta Endocrinol 106: 92-96, 1984.

MORLEY JE, KLEIN C, KALK WJ, JOFFE BI, SAFFER D, DISTILLER LA, SEFTEL HC: Pituitary responsivness to thyrotropin releasing hormone in insulin-dependent diabetes mellitus. Horm Metab Res 10: 231-232, 1978.

NAEIJE R, GOLSTEIN J, CLUMECK N, MEINHOLD H, WENZEL KW, VANHAEIST L: A low T3 syndrome in diabetic ketoacidosis. Clin Endocrinol (Oxf) 8: 467-472, 1978.

PAN CY, LU JM, CHANG XM, LUO GC, LI H: Non-specific response of serum growth hormone to thyrotropinreleasing hormone in diabetics. Chin Med J 102: 41-44, 1989.

PRÁZNÝ M, ŠKRHA J, LIMANOVÁ Z, VANÍČKOVÁ Z, GILBERTOVÁ J, JAREŠOVÁ M, STŘÍŽ I : Screening for associated autoimmunity in type 1 diabetes mellitus with respect to diabetes control. Physiol Res 54: 41-48, 2005.

RADETTI G, DREI F, FRANZELLIN F, PASQUINO B, MENGARDA G: Thyroid function in type 1 juvenile diabetes mellitus: tendency to the low T3 syndrome. Helv Pediatr Acta 40: 461- 466, 1985.

RONDEEL JM, DE GREEF WJ, HEIDE R, VISSER TJ: Hypothalamo-hypophysial-thyroid axis in streptozocininduced diabetes. Endocrinology 130: 216-220, 1992.

SAGESE G, CESARETTI G, BRACALONI C, CALISTI L, CARLOTTI C, CIONI C: Growth hormone secretion in response to the administration of thyrotropin releasing hormone (TRH) in children with insulin-dependent diabetes mellitus. Minerv Pediatr 44: 195-224, 1992.

SNYDER PJ, UTIGER RD: Response to thyrotropin releasing hormone (TRH) in normal man. $J$ Clin Endocrinol Metab 34: 380-385, 1972.

VANELLI M, BERNASCONI S, BOLONDI O, MAMI C, PANDULLO E, SCAFFIDI M, SIRACUSANO MF, DE LUCA F: Effects of intravenous TRH on growth hormone and cortisol serum levels in children and adolescents with insulin dependent diabetes mellitus. J Endocrinol Invest 9: 293-297, 1986.

VISSER T: Biosynthesis transport, metabolism and actions of thyroid hormones. In: Oxford Textbook of Endocrinology and Diabetes. JAH WASS, SM SHALET (eds), Oxford University Press, 2002, pp 287-301.

WÜRZBURGER MI, PRELEVIC GM, SÖNKSEN PH, PERIC LA., TILL S, MORRIS RW: Effects of improved blood glucose on insulin-induced hypoglycaemia, TRH, GnRH and exercise tests in insulin-dependent diabetes, Clin Endocrinol 32: 799-807, 1990.

VONDRA K, VRBIKOVÁ J, BENDLOVÁ B, DVOŘÁKOVÁ K, ŠTERZL I, VONDROVÁ M: Differences in Type I diabetes mellitus of young adults with and without thyroid autoimmunity. Exp Clin Endocrinol Diabetes 113: 404-408, 2005. 